\title{
Medical Components of Psychosexual Pathways: Medications and Erectile Devices
}

Pavlovich et al., [1] examined use of sildenafil (a tablet to cause erections, a PDE5 inhibitor) as part of a randomised controlled trial $(\mathrm{In}=100)$. These results were strong and highlighted a requirement for psychosexual care (Level 1, recommendation A) [1]. This is based on a study design of a randomised controlled trial, good figures, and little loss to follow-up, and appropriately drawn conclusions. The paper highlighted psychosexual care is lacking, including pathways.

Miller et al., [2] examined use of erectile devices as part of sexual motivation. It was a cohort study, between different types of radical therapy with a separate control group [2]. However, although the figures are strong $(n=896)$, and the cohorts within each category would have benefitted from having control groups from each kind of radical therapy to properly assess as the impact of erectile aids on psychosexual care. No sample size was calculated or statistics applied. The results would have been far stronger that way. What is pointed out is the requirement for psychosexual care as part of a pathway (Level 2b, Recommendation B).

\section{References}

1. Pavlovich CP, Levinson AW, Su LM, Mettee LZ, Feng Z, Bivalacqua TJ, Trock BJ. Nightly vs on-demand sildenafil for penile rehabilitation after minimally invasive nerve-sparing radical prostatectomy: results of a randomized double-blind trial with placebo. BJU Int. 2013;112:844-51.

2. Miller DC, Wei JT, Dunn RL, Montie JE, Pimentel H, Sandler HM, McLaughlin PW, Sanda MG. Use of medications or devices for erectile dysfunction among long-term prostate cancer treatment survivors: potential influence of sexual motivation and/or indifference. Urology. 2006;68:166-71. 